\title{
Influence of Graphene Oxide on Interfacial Transition Zone of Mortar
}

\author{
Hongfang Sun $\mathbb{D},{ }^{1}$ Zhili Ren, ${ }^{1}$ Li Ling, ${ }^{1}$ Shazim Ali Memon $\mathbb{D}^{2}{ }^{2}$ Jie Ren, ${ }^{1}$ Bing Liu, ${ }^{3}$ \\ and Feng Xing ${ }^{1}{ }^{1}$ \\ ${ }^{1}$ Guangdong Provincial Key Laboratory of Durability for Marine Civil Engineering, College of Civil and Transportation Engineering, \\ Shenzhen University, Shenzhen 518060, China \\ ${ }^{2}$ Department of Civil Engineering and Environmental Engineering, School of Engineering and Digital Sciences, \\ Nazarbayev University, Astana 010000, Kazakhstan \\ ${ }^{3}$ Shenzhen Institute of Information Technology, Shenzhen 518172, China
}

Correspondence should be addressed to Feng Xing; xingf@szu.edu.cn

Received 29 October 2019; Revised 3 January 2020; Accepted 3 February 2020; Published 19 February 2020

Academic Editor: Giuseppe Compagnini

Copyright (c) 2020 Hongfang Sun et al. This is an open access article distributed under the Creative Commons Attribution License, which permits unrestricted use, distribution, and reproduction in any medium, provided the original work is properly cited.

In this paper, the influence of graphene oxide (GO) on the microstructure of interfacial transition zone (ITZ) in cement mortar was investigated through image analysis (IA) of backscattered electron (BSE) micrographs. The results showed that the incorporation of GO significantly reduced the thickness of ITZ. The porosity in ITZ and bulk paste decreased due to the introduction of GO; meanwhile, the compressive strength of the mortar samples was improved. The addition of GO also narrowed the gap between the porosity of ITZ and bulk paste, and therefore, the entire microstructure of mortar became more homogenous. Based on the above results, the model to predict the compressive strength of mortar was modified for better precision. The improved prediction model indicated that the difference between the compressive strength of ITZ and bulk paste was reduced upon the refinement of ITZ by GO.

\section{Introduction}

Graphene oxide (GO) has Young's modulus and tensile strength of approximately $1100 \mathrm{GPa}$ and $125 \mathrm{GPa}$, respectively, and the super-high specific surface of approximately $2600 \mathrm{~m}^{2} / \mathrm{g}$ [1]. Such properties enable GO to act as reinforcement material in concrete to improve its mechanical performance. The enhancement of the mechanical properties of $\mathrm{GO} /$ cement composites has been widely reported $[2,3]$. For example, Pan et al. [4] found that the addition of $0.05 \mathrm{wt} \%$ of GO increased the compressive strength of concrete by $15-33 \%$ and flexural strength by $41-59 \%$. The elastic modulus of concrete also increased from $3.48 \mathrm{GPa}$ to $3.70 \mathrm{GPa}$. Lv et al. [3] reported that merely $0.02 \mathrm{wt} \%$ of GO could improve the tensile strength and flexural strength of cement paste by $97.2 \%$ and $84.5 \%$, respectively.

The enhancement of mechanical properties was considered to attribute to the refinement of microstructure due to the incorporation of GO. Pan et al. [4] found that GO can refine the pore structure in cement paste. It increased the proportion of gel pores (especially the pore size ranging $1-45 \mu \mathrm{m})$ while reducing the percentage of micro/macro pores. The pore size distribution of cement paste became more uniform [4] when GO was introduced. Researchers have also found that $\mathrm{GO}$ was able to refine the crystal size of cement hydration products $[2,5]$, and this led to increased compressive strength, flexural strength, and tensile strength by $38.9 \%, 60.7 \%$, and $78.6 \%$, respectively [5].

At microscale, concrete systems can be divided into three parts: aggregate, bulk paste, and the interfacial transition zone (ITZ) [6]. Among the three parts, ITZ is usually the weakest part of concrete under loads since the porosity and calcium hydroxide $(\mathrm{CH})$ content in ITZ are higher than those in the bulk paste $[7,8]$. Therefore, the improvement of the structure of ITZ can potentially enhance the mechanical properties of concrete. One effective way to improve the properties of ITZ is to incorporate mineral admixtures into concrete. For example, Bentz and Garboczi found that the 
TABLE 1: The chemical composition and physical properties of PC.

\begin{tabular}{lc}
\hline Chemical composition & Percentage by mass (\%) \\
\hline $\mathrm{CaO}$ & 65.36 \\
$\mathrm{SiO}_{2}$ & 22.15 \\
$\mathrm{Al}_{2} \mathrm{O}_{3}$ & 4.51 \\
$\mathrm{Fe}_{2} \mathrm{O}_{3}$ & 3.39 \\
$\mathrm{MgO}$ & 2.31 \\
$\mathrm{SO}_{3}$ & 0.46 \\
$\mathrm{Na}_{2} \mathrm{O}$ equivalent & 0.488 \\
$f-\mathrm{CaO}$ & 0.95 \\
\hline Physical properties & \\
\hline Specific gravity & 3.15 \\
Fineness $\left(\mathrm{m}^{2} / \mathrm{kg}\right)$ & 346 \\
\hline
\end{tabular}

TABle 2: Physical properties of the graphene oxide.

\begin{tabular}{lc}
\hline Purity $($ wt $\%)$ & $>95$ \\
Thickness $(\mathrm{nm})$ & $3.4-8$ \\
Diameter of slice $(\mathrm{nm})$ & $10-50$ \\
Number of layers & $5-10$ \\
Surface area $\left(\mathrm{m}^{2} / \mathrm{g}\right)$ & $100-300$ \\
\hline
\end{tabular}

addition of silica fume could reduce the porosity of the ITZ [9]. Gao et al. suggested that the blast furnace slag not only refined the $\mathrm{CH}$ crystal in the ITZ but also reduced its content [10]. Kuroda et al. found that fly ash, which had a high $\mathrm{CaO}$ and low $\mathrm{SiO}_{2}$ content, could also reduce the porosity of ITZ and thereby increased the overall strength of the system [11]. Similarly, as a typical nanomaterial, GO is also expected to enhance the ITZ of concrete.

Until now, researchers have only focused on evaluating the influence of GO on the bulk paste $[5,12]$. However, the ITZ performance has not been investigated thoroughly when $\mathrm{GO}$ is incorporated. The composition of ITZ differs from bulk paste in terms of water to cement ratio, porosity, and hydration products, and GO can significantly influence these parameters [13]. Therefore, in this research, the influence of $\mathrm{GO}$ on microscopic properties (such as porosity and volume fraction of unhydrated cement) of ITZ in mortar was studied through a BSE image segmentation method. Based on the results, the model to predict compressive strength was reported. This work will contribute to the development of relationships between microstructure and macroscopic properties in cement mortar incorporating GO.

\section{Materials and Methods}

2.1. Materials. In this research, cement mortars were prepared to study the influence of GO on ITZ. The materials used for the preparation of mortars include Portland cement (PC), GO, deionized water, and sand. The composition and physical properties of PC (China United Cement Group Co. Ltd.) are shown in Table 1. GO is used as an admixture and its physical properties are enlisted in Table 2. Standard
Table 3: Particle size distribution of the sand obtained from sieving method.

\begin{tabular}{lcc}
\hline No. $(k)$ & $\begin{array}{c}\text { Diameter range } \\
d_{k}(\mathrm{~mm})\end{array}$ & $\begin{array}{c}\text { Volume fraction } \\
c_{k}(\%)\end{array}$ \\
\hline 1 & $>5$ & 0.00 \\
2 & $2-5$ & 8.47 \\
3 & $1-2$ & 23.62 \\
4 & $0.5-1$ & 35.28 \\
5 & $0.25-0.5$ & 3.65 \\
6 & $0.1-0.25$ & 28.42 \\
7 & $0.075-0.1$ & 0.52 \\
8 & $0-0.075$ & 0.05 \\
\hline
\end{tabular}

TABLE 4: Mix proportion of cement mortar.

\begin{tabular}{lccc}
\hline $\begin{array}{l}\text { Specimen } \\
\text { identification }\end{array}$ & $w / b$ & $\begin{array}{c}\text { PC } \\
\text { (wt\%) }\end{array}$ & $\begin{array}{c}\mathrm{GO} \\
\text { (wt\%) }\end{array}$ \\
\hline PC 0.35 & 0.35 & 100 & - \\
PC 0.45 & 0.45 & & \\
PC 0.55 & 0.55 & & \\
\hline PC/GO 0.35 & 0.35 & 99.92 & 0.08 \\
PC/GO 0.45 & 0.45 & & \\
PC/GO 0.55 & 0.55 & & \\
\hline
\end{tabular}

quartz sand (China ISO Standard Sand Co. Ltd.) with a specific gravity of 2.65 is used as fine aggregates. The gradation of the sand is shown in Table 3.

2.2. Specimen Preparation. The details of mixture proportion for mortar specimens are shown in Table 4. In total, six mixtures were prepared with three different water to binder ratios $(w / b=0.35,0.45$, and 0.55 , respectively). PC represents the control specimen while PC/GO indicates the specimens incorporating GO. For the preparation of PC/GO specimen, GO was added to the deionized water followed by the ultrasonication of mixture for 30 minutes. This mixture was subsequently mixed with cement and sand to prepare PC/GO mortar. The binder $(\mathrm{PC}+\mathrm{GO})$ to sand ratio $(b / s)$ was kept at $1: 3$ by mass. After casting, the specimens with size of 40 $\mathrm{mm} \times 40 \mathrm{~mm} \times 40 \mathrm{~mm}$ were cured for 24 hours. Thereafter, the specimens were demolded and cured until 28 days in deionized water at $20 \pm 2^{\circ} \mathrm{C}$.

\subsection{Testing Methods}

2.3.1. Backscattered Electron (BSE) Method. In this research, BSE method was used to investigate the porosity and volume of unhydrated cement in ITZ and bulk cement paste. For this purpose, a polished cross section was required. The samples were firstly impregnated with low-viscosity epoxy under vacuum to avoid the collapse of pores during polishing. After epoxy impregnation, the samples were cut to expose a fresh surface and roughly polished using 600 and 1200 grade $\mathrm{SiC}$ paper. The flat sections were then polished progressively using diamond paste with the particle size of $14 \mu \mathrm{m}, 3.5 \mu \mathrm{m}$, 
$1 \mu \mathrm{m}$, and $0.25 \mu \mathrm{m}$. Ultrasonication was used to clean the samples between steps. Finally, the polished samples were coated with a very thin layer of gold to obtain a conductive surface for SEM analysis.

BSE was performed on a FEI Quanta 250 scanning electron microscope with a cold field emission gun. The images were taken at an acceleration voltage of $20 \mathrm{kV}$ under high vacuum and at a magnification of $\times 800$. Each BSE image consisted of $1536 \times 1023$ pixels with 256 integral gray level ranging from 0 (black) to 255 (white). The spatial resolution ratio of BSE images was $0.34 \mu \mathrm{m}$ which indicated that the minimum size of pores that can be observed under this setting was $0.34 \mu \mathrm{m}$. For each specimen, approximately 35 images were randomly selected. The porosity and volume fraction of the unhydrated cement in ITZ were later analyzed through image analysis (IA).

2.3.2. Compressive Strength. The compressive strength of mortar specimens was determined at the age of 28 days according to the standard of BS EN 196-1 [14] using YZH300.10 compression machine (Shenzhen Kedao Experimental Equipment Co., Ltd., Shenzhen, China). For each mixture design, three samples were tested and the average value was reported.

\section{Image Analysis}

3.1. Grayscale Normalization. The porosity and volume fraction of unhydrated cement in ITZ and bulk paste were calculated based on the area after image segmentation. The area of pores (in percentage) and unhydrated cement (in percentage) observed in BSE images could represent the porosity and volume fraction of unhydrated cement in mortar as mentioned in References [6, 7, 15]. However, in order to obtain the porosity and volume fraction of unhydrated cement in mortar, the threshold should be determined. Fixed threshold is a commonly used approach to reduce the workload. However, the change of surface roughness and local conductance may affect the accuracy of the results using this method. Another way is to adjust the threshold according to visual observation, but it is a subjective method which may not be precise. Therefore, the normalization of grayscale of BSE images was performed using a method proposed by Yao et al. [16] and described in the following paragraph.

Consider two BSE images as shown in Figure 1. Figure 1(a) is the reference image while Figure 1(d) is the image that needs to be analyzed. The threshold of the latter will be expressed in terms of the threshold of the former and other known parameters. For each image, two phases $\left(\mathrm{C}-\mathrm{S}-\mathrm{H}\right.$ and $\left.\mathrm{C}_{3} \mathrm{~S}\right)$ are considered, which are usually the main compositions obtained after hydration and easy to distinguish in the BSE images. Assume the gray values of C-S-H and $\mathrm{C}_{3} \mathrm{~S}$ to be $G_{r}^{\mathrm{CSH}}$ and $G_{r}^{\mathrm{C}_{3} \mathrm{~S}}$ for the reference image and $G_{i}^{\mathrm{CSH}}$ and $G_{i}^{\mathrm{C}_{3} \mathrm{~S}}$ for the image to be analyzed. The threshold for the constituent of interest (such as pores) in reference and analyzed images are assumed to be $P_{r}$ and $P_{i}$, respectively. If the grayscale of $\mathrm{C}-\mathrm{S}-\mathrm{H}$ and $\mathrm{C}_{3} \mathrm{~S}$ was set exactly the same for different images, then the grayscale for pores in dif- ferent images should also be the same. In other words, they have been adjusted to the same level. This can be achieved by multiplication and translation operations. Thus, the threshold of the constituent of interest is

$$
P_{i}=G_{i}^{\mathrm{CSH}}+\left(P_{r}-G_{r}^{\mathrm{CSH}}\right) \frac{G_{i}^{\mathrm{CSH}}-G_{i}^{\mathrm{C}_{3} \mathrm{~S}}}{G_{r}^{\mathrm{CSH}}-G_{r}^{\mathrm{C}_{3} \mathrm{~S}}} .
$$

An example of grayscale normalization of BSE images where the pores were segmented is shown in Figure 1. Figure 1(a) represents the reference image while Figure 1(d) indicates the image that needs to be analyzed. Figures 1(b) and $1(\mathrm{e})$ are the corresponding histogram images, where two distinct peaks are observed. The peaks represent hydration products (HP) and unhydrated cement (UC), respectively [17]. Assuming that the maximum peak represents the grayscale of C-S- $\mathrm{H}$ and $\mathrm{C}_{3} \mathrm{~S}$, the obtained values of grayscales are $G_{r}^{\mathrm{CSH}}=156, G_{r}^{\mathrm{C}_{3} \mathrm{~S}}=243, G_{i}^{\mathrm{CSH}}=151$, and $G_{i}^{\mathrm{C}_{3} \mathrm{~S}}=213$. For the reference image, assuming the threshold for the pores as $P_{r}=76$, then the segmented pore structure with the aggregate excluded is presented in Figure 1(c). According to equation (1), the threshold for the pores in the image of interest is $P_{i}=72$. The extracted pores for Figure 1(d) are shown in Figure 1(f).

The threshold for unhydrated cement is selected from the minimum peaks between HP and UC on histogram as indicated by the dotted line in Figures 1(b) and 1(e) [18], which can be used to estimate the volume fraction of unhydrated cement.

3.2. Calculation of Porosity and Volume Fraction of Unhydrated Cement of ITZ. Based on the aforementioned processing method, the porosity and volume fraction of unhydrated cement in ITZ as well as in bulk paste can be calculated. However, before that, the area of interest should be determined. The typical thickness of ITZ reported in literature $[6,7,19]$ is between 20 and $50 \mu \mathrm{m}$. Therefore, the $100 \mu \mathrm{m}$ region from the edge of aggregate (sand) was analyzed, as shown in Figure 2(a). This $100 \mu \mathrm{m}$ region included both the ITZ and bulk paste. After determining the area of interest (the $100 \mu \mathrm{m}$ region), in the next stage, the region was divided into 10 equal strips according to the distance from the edge of the sand as shown in Figure 2(b). Next, the porosity and volume fraction of unhydrated cement in each strip were calculated. An example is shown in Figure 2(c), according to which, a plot of the porosity versus the distance from the edge of the aggregate was drawn to determine the thickness of ITZ.

To ensure that the results are statistically significant, approximately 35 BSE images were analyzed for each specimen. The thickness of ITZ, porosity, and volume fraction of unhydrated cement of the ITZ as well as bulk paste for each specimen were determined, and the average values from the 35 images were used. It should be noticed that these images were taken from different sand particles having varying particle sizes. Moreover, during image acquisition, these sand particles were randomly selected. Hence, the average value 


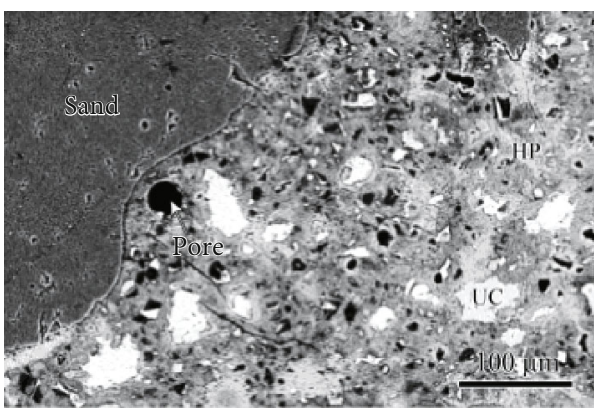

(a)

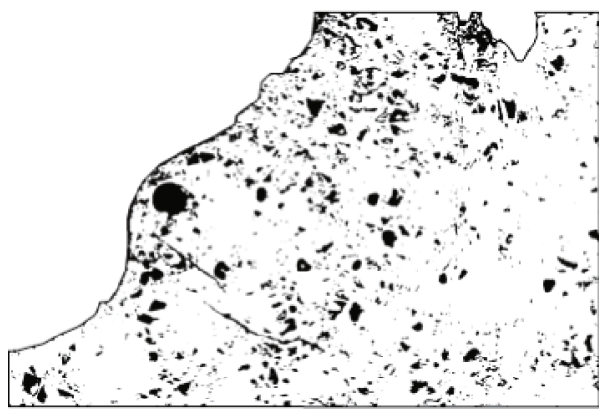

(c)

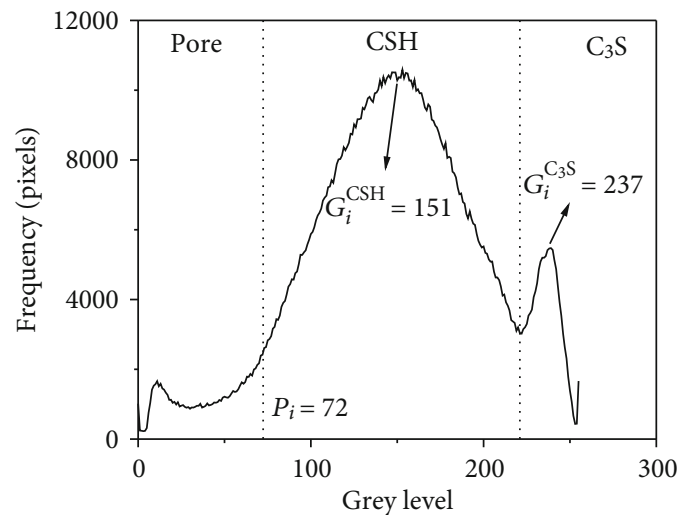

(e)

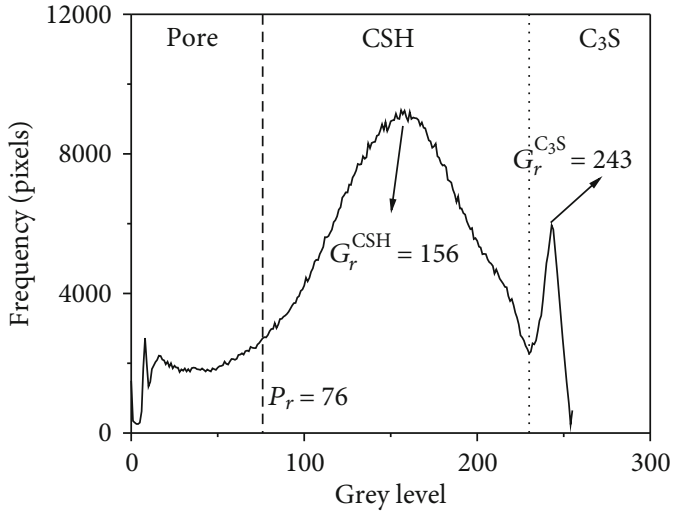

(b)

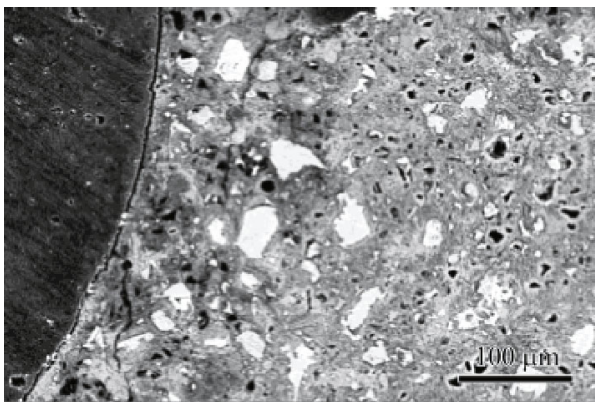

(d)

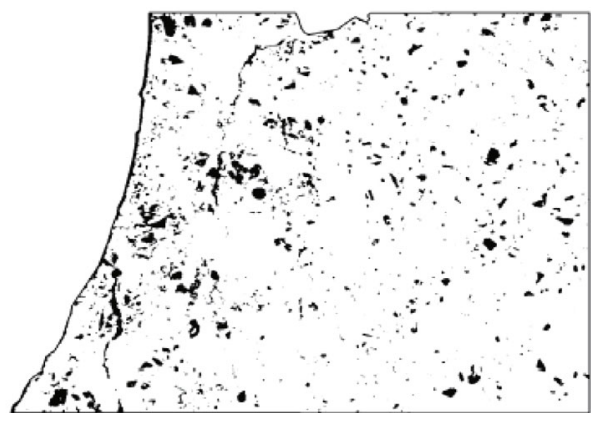

(f)

FIGURE 1: An example of grayscale normalization of BSE images. (a) Reference image. (b) Gray level histogram of cement paste in (a). (c) Segmented pores in (a) (grayscale range: 0-76). (d) Image to be analyzed. (e) Gray level histogram of cement paste in (d). (f) Segmented pores of image in (d) (grayscale range: $0-72$ ).

from these 35 images was counted in the contribution of sand particles with different particle sizes.

The average porosity of the whole specimen (including the contribution from both ITZ and bulk paste) can be calculated as follows:

$$
p=V_{\mathrm{ITZ}} \times p_{\mathrm{ITZ}}+\left(1-V_{\text {sand }}-V_{\mathrm{ITZ}}\right) \times p_{\text {bulk }},
$$

where $p_{\text {ITZ }}$ represents the average porosity of ITZ; $p_{\text {bulk }}$ represents the average porosity of bulk paste; $V_{\text {sand }}$ is the volume fraction of the sand in mortar, and $V_{\text {ITZ }}$ represents the volume fraction of ITZ in mortar. The values of sand, cement, and water $\left(V_{\text {sand }}, V_{\text {cem }}\right.$, and $\left.V_{\mathrm{w}}\right)$ were calculated from the mix proportion of mortar. The results are presented in Table 5. It should be noticed that the mix proportions for $\mathrm{PC}$ and PC/GO were approximately the same since the content of GO used in this research is very low $(0.08 \%$ of binder).

The volume fraction of ITZ in mortar $\left(V_{\text {ITZ }}\right)$ was calculated by using equation (3) [20-22]:

$$
V_{\text {ITZ }}=1-e_{V}\left(t_{\mathrm{ITZ}}\right)-V_{\text {sand }},
$$

where $e_{V}\left(t_{\mathrm{ITZ}}\right)$ represents "void exclusion probability." It refers to the volume fraction of the remaining area in 


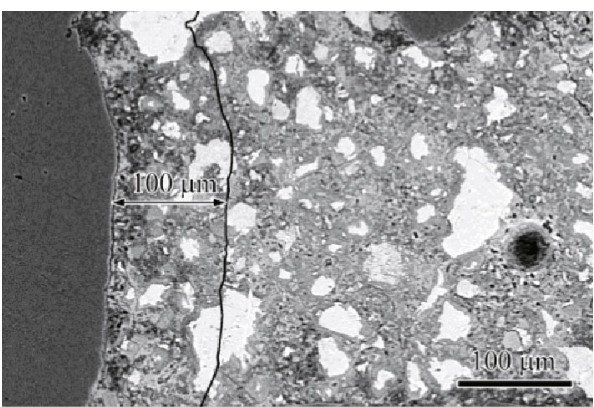

(a)

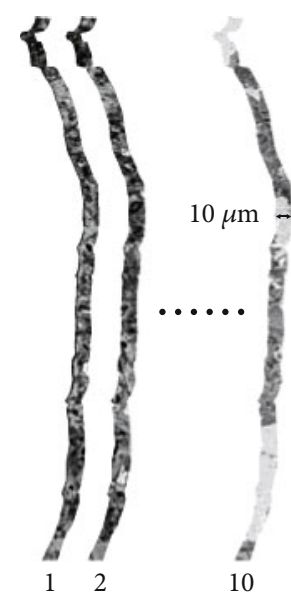

(b)

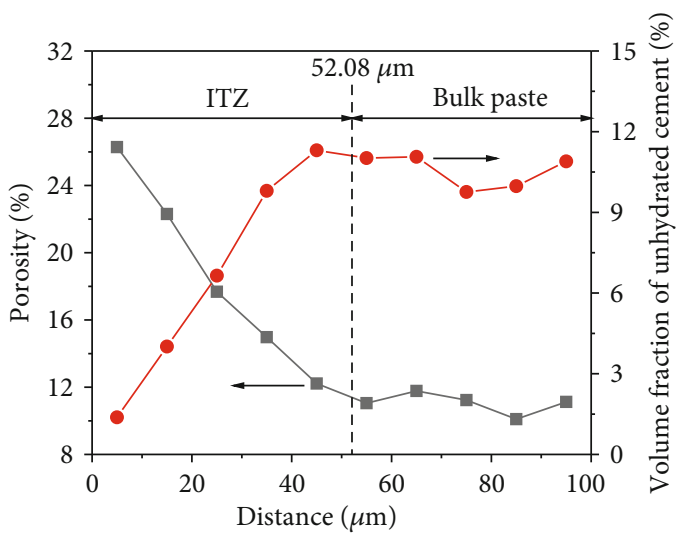

(c)

FIGURE 2: Segmentation of ITZ in cement paste. (a) A typical BSE image of cement mortar; (b) segmented ITZ; (c) porosity and volume fraction of unhydrated cement vs. distance from the edge of the aggregate.

TABle 5: Volume fraction of cement paste, sand, and water.

\begin{tabular}{lccc}
\hline & \multicolumn{3}{c}{ Volume fraction (\%) } \\
Specimen & $\begin{array}{c}\text { Cement } \\
\left(V_{\text {cem }}\right)\end{array}$ & $\begin{array}{c}\text { Sand } \\
\left(V_{\text {sand }}\right)\end{array}$ & $\begin{array}{c}\text { Water } \\
\left(V_{\mathrm{w}}\right)\end{array}$ \\
\hline PC 0.35 or PC/GO 0.35 & 17.64 & 62.91 & 19.45 \\
PC 0.45 or PC/GO 0.45 & 16.71 & 59.60 & 23.69 \\
PC 0.55 or PC/GO 0.55 & 15.88 & 56.62 & 27.51 \\
\hline
\end{tabular}

concrete except the ITZ and aggregate [20,23]. It can be calculated by equation (4).

$e_{V}\left(t_{\mathrm{ITZ}}\right)=\left(1-V_{\text {sand }}\right) \cdot \exp \left[-\pi \cdot N_{\text {sand }}\left(c t_{\mathrm{ITZ}}+d t_{\mathrm{ITZ}}^{2}+g t_{\mathrm{ITZ}}{ }^{3}\right)\right]$,

where $N_{\text {sand }}$ represents the number of sands per $100 \mathrm{~cm}^{3}$ of mortar, and $t_{\text {ITZ }}$ is the thickness of ITZ of the specimen while the parameters $c, d$, and $g$ represent the average grain size of the sand and can be calculated by using [20-22]

$$
\begin{aligned}
& c=\frac{4\left\langle R^{2}\right\rangle}{1-V_{\text {sand }}}, \\
& d=\frac{4\langle R\rangle}{1-V_{\text {sand }}}+\frac{12 \zeta_{2}\left\langle R^{2}\right\rangle}{\left(1-V_{\text {sand }}\right)^{2}}, \\
& g=\frac{4}{3\left(1-V_{\text {sand }}\right)}+\frac{8 \zeta_{2}\langle R\rangle}{\left(1-V_{\text {sand }}\right)^{2}}+\frac{16 A \zeta_{2}^{2}\left\langle R^{2}\right\rangle}{3\left(1-V_{\text {sand }}\right)^{3}},
\end{aligned}
$$

where

$$
\zeta_{2}=\frac{2}{3} \pi \cdot V_{\text {sand }}\left\langle R^{2}\right\rangle
$$

In equation (7), $A$ is a regression coefficient. For concrete system, $A=0$ showed the best results in terms of curve fitting [20].

The value of $\langle R\rangle$ and $\left\langle R^{2}\right\rangle$ in equations (6), (7) and (8) represents the average radius and the square of radius of sand, respectively. The value of $N_{\text {sand }}$ in equation (4) and $\langle R\rangle$ can be obtained from the particle size distribution of the sand (sieving method) through $[20,21]$

$$
\begin{aligned}
N_{\text {sand }} & =\sum_{i=k}^{M} \frac{9 V_{\text {sand }} c_{k}}{4 \pi\left(r_{k+1}^{3}-r_{k}^{3}\right)} \ln \left(\frac{r_{k+1}}{r_{k}}\right), \\
\left\langle R^{n}\right\rangle & =\sum_{k=1}^{M} \frac{9 V_{\text {sand }} c_{k}}{4 \pi N_{\text {sand }}\left(r_{k+1}^{3}-r_{k}^{3}\right)} \int_{r_{k}}^{r_{k+1}} r^{n-1} d r,
\end{aligned}
$$

where $M$ is the total number of sieves used; $r_{k}$ is half of the diameter of the sieve, i.e., $r_{k}=1 / 2 \times d_{k} ; c_{k}$ is the volume fraction of sand in the diameter between $d_{k}$ and $d_{k+1}$, which can be obtained by dividing the remaining mass of the sand on each sieve by the density of sand. The obtained particle size distribution of the sand is shown in Table 3.

The volume fraction of unhydrated cement in ITZ can also be calculated using a similar method to estimate the influence of GO on the hydration degree of cement.

\section{Results and Discussion}

\subsection{Influence of GO on the Thickness and Volume Fraction of ITZ}

4.1.1. Thickness of ITZ. The results of thickness of ITZ for specimens PC and PC/GO with different $w / b$ are presented in Figure 3. The thickness of ITZ in both specimens increased with the increase of $w / b$. This is due to the reason that with an increase in the $w / b$, more water would be available in the system, which has the tendency to be blocked by the 


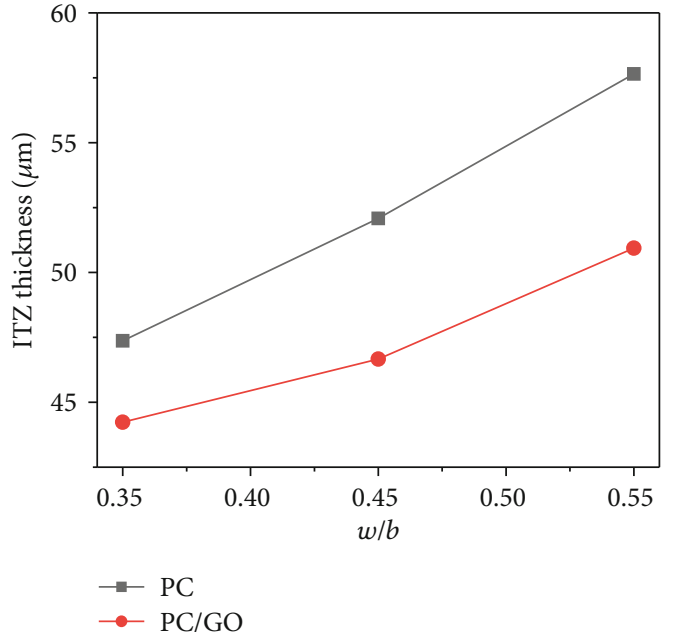

FIgURe 3: Relationship between thickness of ITZ and $w / b$.

aggregate $[7,24]$. This, in turn, will enlarge the thickness of ITZ. At $0.35,0.45$, and 0.55 of $w / b$, the thickness of the ITZ in specimens prepared with GO was reduced by $6.62 \%$, $10.40 \%$, and $11.64 \%$, respectively, when compared with that in the control specimen (specimen PC). This showed that GO was effective in reducing the thickness of ITZ. It can also be noticed that with the increase in the $w / b$, the difference in ITZ thickness between PC and PC/GO specimen increased. In other words, at higher $w / b$, GO was more effective in reducing ITZ thickness. This may be due to the reason that at higher $w / b$, more hydration products formed in ITZ to interact with GO and to regulate the microstructure of ITZ.

4.1.2. Volume Fraction of ITZ. After determining the thickness of ITZ, the volume fraction of ITZ in the mortar can be calculated by using equation (3), which would subsequently be used to calculate the total porosity of the mortar. The results of volume fraction of ITZ for specimen PC and PC/GO are shown in Figure 4 and Table 6. For the control specimen PC, the volume fraction of ITZ in mortar increased from $15.32 \%$ to $17.29 \%$ with the increase in $w / b$ from 0.35 to 0.55 , respectively, while for the PC/GO specimen, the volume fraction of ITZ in mortar increased from $14.32 \%$ to $15.25 \%$. From the results, we can see that for both of the specimens, the volume fraction of ITZ was approximately $15 \%$ of the total volume of mortar (approximately $40 \%$ of the cement paste part in mortar, Table 6), which suggests that ITZ is an important part of the mortar. Moreover, in comparison to the control specimen, the volume fraction of ITZ in the PC/GO specimen significantly decreased at varied $w / b$, which means that the incorporation of GO could reduce the impact of ITZ on the whole mortar.

4.2. Influence of $G O$ on Porosity. By using the image processing method described in Section 3, the porosity of ITZ and bulk paste $\left(p_{\text {ITZ }}\right.$ and $\left.p_{\text {bulk }}\right)$ for both specimens was obtained. The results are presented in Figure 5. For both specimens, the porosity in ITZ and bulk paste increased with the increase of

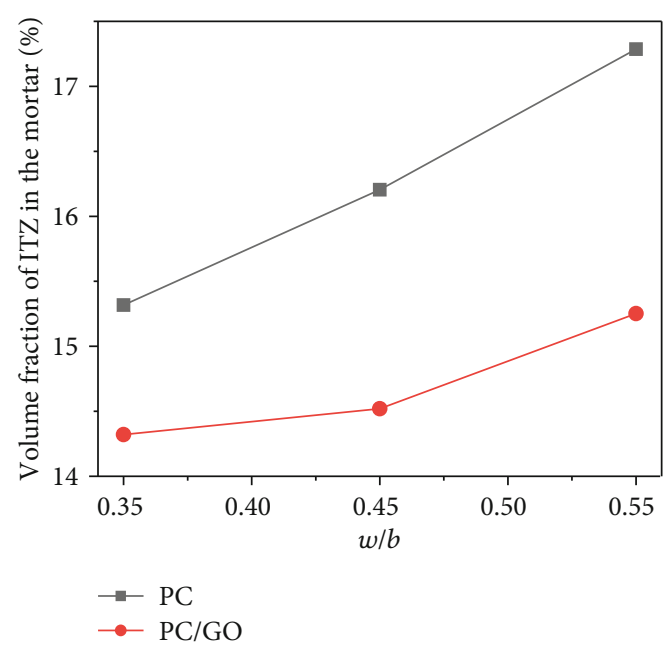

FIgUre 4: The volume fraction of ITZ vs. $w / b$ in PC and PC/GO specimens.

TABLE 6: The volume fraction of ITZ, bulk paste, and sand of mortar and the volume fraction of ITZ of the cement paste part in mortar (\%).

\begin{tabular}{lcccc}
\hline Specimens $(w / b)$ & $V_{\text {ITZ }}$ & $V_{\text {bulk }}$ & $V_{\text {sand }}$ & $\begin{array}{c}\text { Volume fraction of } \\
\text { ITZ in paste }\end{array}$ \\
\hline PC (0.35) & 15.32 & 21.77 & 62.91 & 41.30 \\
PC (0.45) & 16.20 & 24.20 & 59.60 & 40.10 \\
PC (0.55) & 17.29 & 26.09 & 56.62 & 39.86 \\
PC/GO (0.35) & 14.32 & 22.77 & 62.91 & 38.61 \\
PC/GO (0.45) & 14.52 & 25.88 & 59.60 & 35.94 \\
PC/GO (0.55) & 15.25 & 28.13 & 56.62 & 35.15 \\
\hline
\end{tabular}

$w / b$ (Figure 5(a)). This may be explained by the reason that at higher $w / b$ more water would be available in ITZ and bulk paste, resulting in the formation of more pores [7]. Moreover, for both specimens, the porosity in ITZ was significantly larger than that in the bulk paste since the local $w / b$ in ITZ was higher than that of the bulk paste, and this led to larger porosity in ITZ.

In terms of the influence of GO, the addition of GO can significantly reduce the porosity of both ITZ and the bulk paste. At $0.35,0.45$, and 0.55 of $w / b$, the porosity in ITZ of PC/GO specimens was reduced by $64.71 \%, 46.54 \%$, and $28.37 \%$, respectively, when compared with that of control specimens. Similarly, the porosity in bulk paste of PC/GO specimens reduced by $67.16 \%, 53.26 \%$, and $31.45 \%$, respectively. Moreover, it was observed that the difference in porosity between ITZ and bulk paste was reduced when GO was incorporated.

The results of the average porosity in whole mortar are shown in Figure 5(b). In comparison to PC, the specimens prepared with GO reduced the average porosity of the whole specimen in the range from $31.32 \%$ to $66.57 \%$. It should be noted that due to the limitation of BSE image resolution, the size of the pores observed in this research was in between 0.34 and $345.61 \mu \mathrm{m}$. 


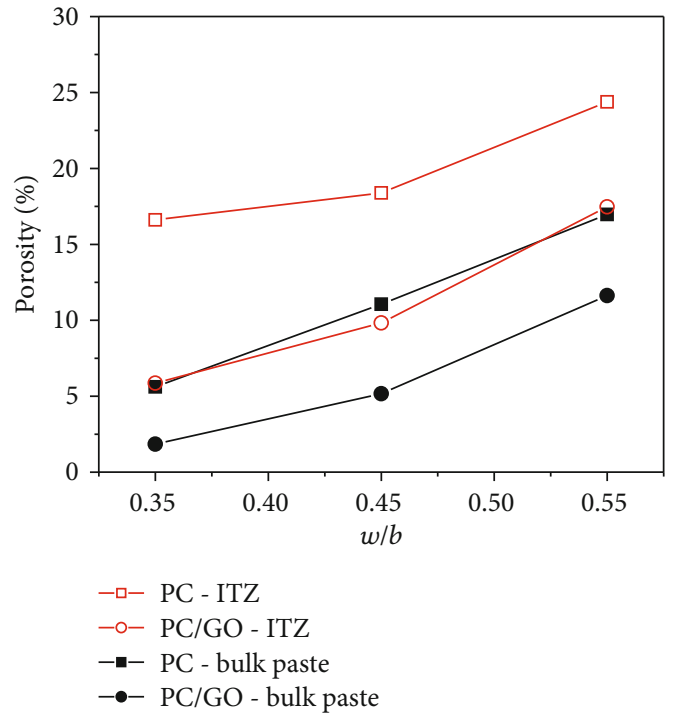

(a)

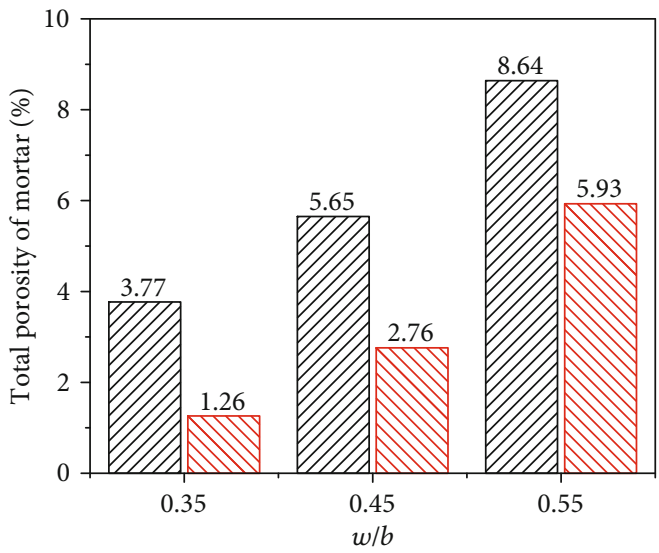

VIII PC MIV PC/GO

FIgure 5: Porosity in specimen PC and PC/GO at varied $w / b$. (a) Porosity in ITZ and bulk paste; (b) porosity in the whole mortar.

In order to further evaluate the impact of ITZ on the whole mortar, the volume fraction of pores in ITZ to the total pores in mortar was calculated and is listed in Table 7. From the results, it can be seen that the pores in ITZ accounted for $45-68 \%$ of the whole pore volume in mortar, proving the importance of ITZ in the mortar system. It is also interesting to notice that the incorporation of GO only slightly reduced the volume fraction of pores in ITZ to total pores in mortar, which indicated that the contribution of ITZ was still important even with GO involved. The increased $w / b$ reduced the volume fraction of pores in ITZ to total pores in mortar since the pores in bulk paste increased more than those in ITZ, indicating that the influence of ITZ was more significant at lower $w / b$.

From the above discussion, it is clear that GO is able to reduce the porosity in cement mortars, which may be related to the following aspects: (1) filler effect [25] (however, the influence of this factor might be negligible since the dosage of GO (0.08\% by mass) was relatively low) and (2) nuclear effect [5], where GO could act as a seed to promote the hydration of cements. In order to determine the exact reason for the reduction in porosity with the addition of GO, the volume fraction of unhydrated cement was extracted from the BSE images. The analysis is presented in the next section.

4.3. Influence of GO on Unhydrated Cement. The fraction of unhydrated cement reflects the degree of hydration of cement since the sum of hydrated and unhydrated cement is a constant. This means that the less the unhydrated cement, the more would be the portion of hydrated cement, which results from a higher degree of hydration. The results of volume fraction of unhydrated cement in ITZ, bulk paste, and whole mortar with/without GO at varied $w / b$ are shown in Figure 6. The volume fraction of unhydrated cement in ITZ was much lower than that in bulk paste. This was reasonable since the local $w / b$ in ITZ was higher than that in bulk
TABLE 7: The volume fraction of pores in ITZ to the total pores in mortar (\%).

\begin{tabular}{lccc}
\hline$w / b$ & 0.35 & 0.45 & 0.55 \\
\hline PC & 67.56 & 52.69 & 48.78 \\
PC/GO & 66.67 & 51.62 & 44.89 \\
\hline
\end{tabular}

paste, which in turn promoted the degree of hydration in ITZ. It can also be noticed that for both specimens (PC and $\mathrm{PC} / \mathrm{GO}$ ), the average volume fraction of unhydrated cement in the whole mortar specimen decreased with the increase in $w / b$. This means that with the increase of $w / b$, the degree of hydration was promoted due to the availability of extra water in specimens prepared with higher $w / b$.

It is interesting to notice that at all $w / b$, the addition of GO only slightly reduced the fraction of unhydrated cement in ITZ, bulk paste, and the whole mortar specimens. The maximum reduction in the volume fraction of unhydrated cement by GO was up to $7.81 \%$, suggesting that until the age of 28 days, the addition of GO on the degree of hydration was insignificant. This means that the reduction in porosity could not be explained by the change of hydration degree. In this study, only pores ranging $0.34-345.61 \mu \mathrm{m}$ were counted considering the resolution limit of BSE technique. Due to magnification limits, the macro pores larger than $345.61 \mu \mathrm{m}$ were not found and nanopores smaller than $0.34 \mu \mathrm{m}$ could not be detected. In Ref. [4], the decrease of microscale porosity was also observed with the incorporation of GO in cement, which was consistent with the finding of this study. However, in the same Ref. [4], the nanoscale gel porosity increased due to the rearrangement of hydration products of cement, which was beyond the detection limit of this study. This might suggest that the decrease of the observed porosity is the result of pore size rearrangement, e.g., from microscale to nanoscale. Despite these limitations, 


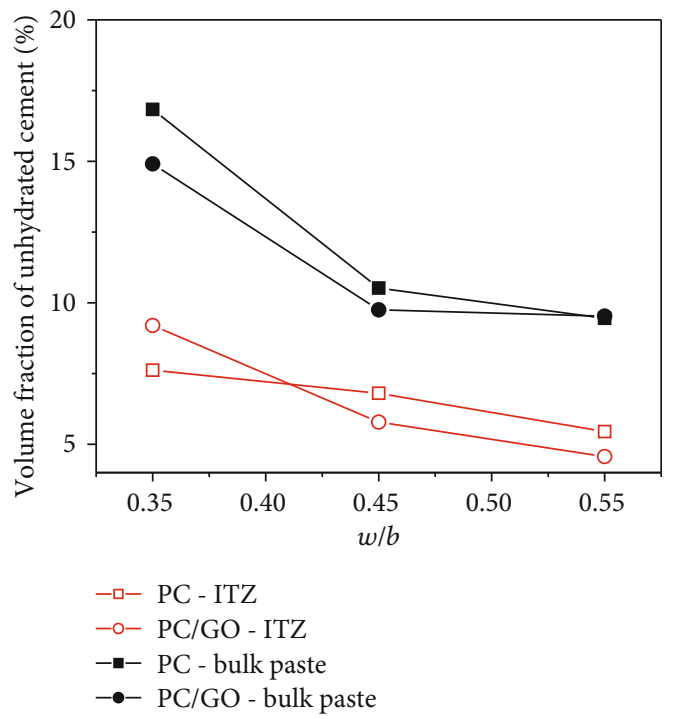

(a)

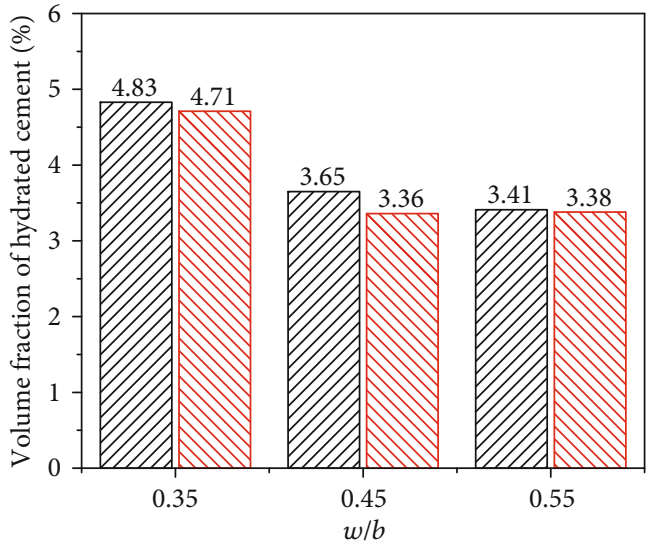

VIIA PC

NIV PC/GO

FIgURE 6: The volume fraction of unhydrated cement in (a) ITZ and bulk paste and in (b) the whole mortar.

the conclusion obtained from this work is still useful since the microscale pores were mainly considered responsible for the degradation of mechanical properties and durability of concrete [26]. Although the influence of pores larger than $345.61 \mu \mathrm{m}$, which were generally air voids, could be more significant, the air voids in mortar could be avoided through sufficient consolidation during the specimen preparation process $[27,28]$.

\subsection{Application of ITZ Investigation-Compressive Strength} Prediction. The extracted microscopic parameters (such as porosity and degree of hydration) of ITZ with GO can be used in predicting the macroscopic properties of mortar. In the following section, as an example, the relationship between the porosity in ITZ and the compressive strength prediction was discussed. Prior to that, the compressive strength of mortar was measured. The influence of GO on the compressive strength was also discussed in the next section.

4.4.1. Influence of GO on Compressive Strength. The results of compressive strength of specimens at various $w / b$ prepared with and without GO are presented in Figure 7. For specimens prepared with and without GO, the compressive strength decreased with the increase of $w / b$. At the same $w /$ $b$, the compressive strength of mortar specimens with GO was higher than the mortar specimen prepared without GO. In comparison to the control specimens, the increment in the compressive strength of specimens with GO was up to $6.76 \%$. The reason for the strength enhancement was generally considered to be related to the porosity of specimen $[29,30]$. The "considered porosity" usually referred to the fraction of open pores that could be easily measured by mercury intrusion porosimetry (MIP) [31]. However, the isolated pores such as air voids also contribute significantly to compressive strength and these pores as well as open pores can be simultaneously counted through the BSE method. Thus,

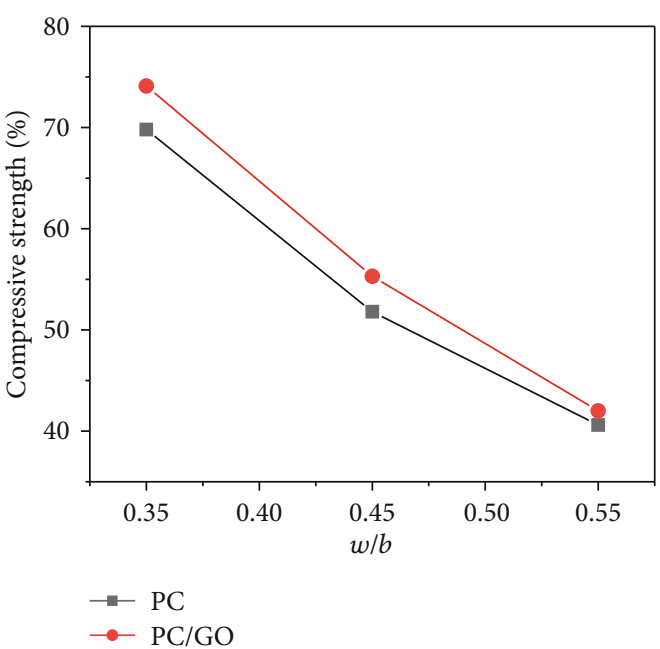

Figure 7: Compressive strength of specimen PC and PC/GO at various $w / b$.

the model established based on the porosity obtained in this research could be more accurate and the correlation between porosity and compressive strength is expected to be more precise.

4.4.2. Strength Prediction Based on Porosity of ITZ. Chen et al. [29] proposed a widely used model describing the relationship between compressive strength and porosity as

$$
\sigma=k \ln \left(\frac{p_{0}}{p}\right),
$$

where $\sigma$ is compressive strength (MPa); $p$ is the porosity of mortar (including the contribution of both ITZ and bulk paste and calculated through equation (2)); $p_{0}$ is the porosity at zero strength with unit of $\% ; k$ is the regression coefficient. 


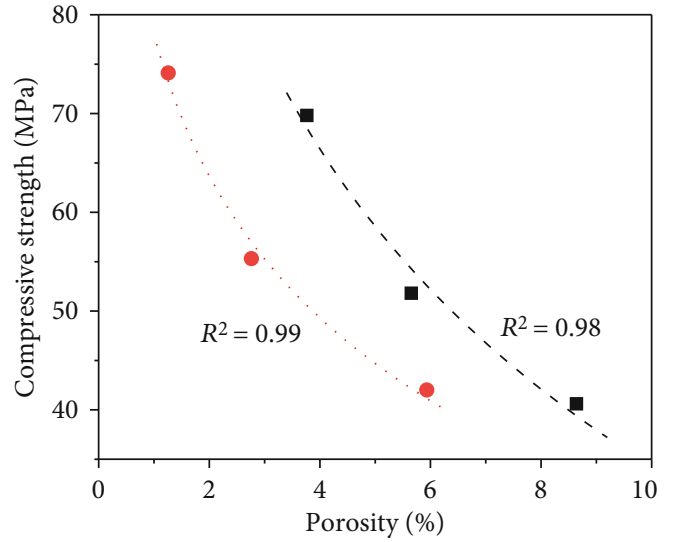

- $\mathrm{PC}$ - measured

- PC/GO - measured

- - PC - fitted

$\mathrm{PC} / \mathrm{GO}$ - fitted

FIGURE 8: Measured compressive strength and porosity with fitted curves based on Schille's model.

By substituting the measured value of $\sigma$ and $p$ for specimen PC and PC/GO into equation (10) and fitting, $p_{0}$ and $k$ can be obtained through regression. Thus, the established model is as follows.

$$
\begin{aligned}
& \sigma=35.09 \times \ln \left(\frac{26.55}{p}\right) \quad(\text { For specimen PC }) \\
& \sigma=20.72 \times \ln \left(\frac{43.24}{p}\right) \quad(\text { For specimen } \mathrm{PC} / \mathrm{GO}) .
\end{aligned}
$$

The results of curve fitting presented in Figure 8 show that for both specimens (PC and PC/GO), the value of $R^{2}$ is greater than 0.98 . Thus, good correlation exists between the measured strength and porosity of mortar. It is worth pointing out that the regressed values of $k$ and $p_{0}$ for specimen PC $\left(k: 35.09\right.$ and $\left.p_{0}: 26.55\right)$ are very close to the value reported in Ref. [31] ( $k: 37.1$ and $\left.p_{0}: 28.4\right)$ where the porosity was obtained through MIP method, thus proving the reliability of the fitting results.

In order to evaluate the contribution of the porosity of ITZ to predict the strength, the compressive strength calculated with/without considering the porosity of ITZ was compared and the results are shown in Figure 9. The calculated strength became larger by at least $10.90 \%$ if the porosity of ITZ was not taken into account. The difference was larger at lower $w / b$, suggesting that the influence level of ITZ becomes more significant when less water was present. This may be due to the reason that the volume fraction of pores in ITZ to total pores in mortar was higher at a lower $w / b$ as shown in Table 7. Similar behavior was observed for PC/GO specimens, e.g., the calculated strength became larger when the porosity of ITZ was not considered.

However, it is also interesting to notice that for PC/GO specimen, the difference between the strength with/without considering ITZ was smaller than that of the control speci-

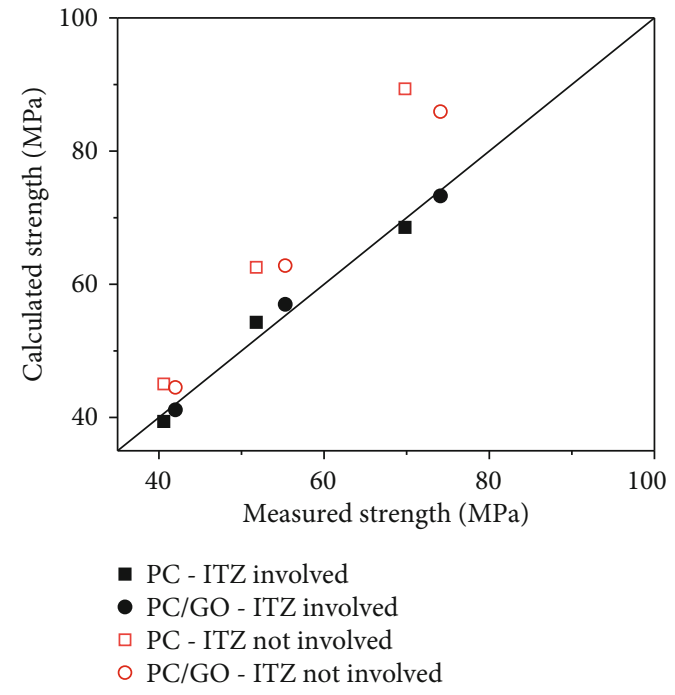

FIgURE 9: Prediction of compressive strength with/without considering the porosity of ITZ.

men. It indicated that the incorporation of GO can reduce the influence of ITZ on the strength. Therefore, by considering the microfeatures of ITZ, the accuracy of prediction at macro level will be significantly improved for cementitious materials.

\section{Conclusions}

In this research, the effect of GO on ITZ of mortar was investigated through segmentation of BSE images. Based on the results, the following conclusions can be drawn.

(1) For the mortar with $b / s$ of $1: 3$ and $w / b$ from 0.35 to 0.55 , the volume fraction of ITZ was approximately $15 \%$ of the total volume of mortar (approximately $40 \%$ of the cement paste part in mortar). The pores in ITZ accounted for $45-68 \%$ of the whole pore volume in mortar, proving the necessity to investigate the effect of ITZ in the mortar system

(2) With the incorporation of GO in mortar, the thickness and volume fraction of ITZ was effectively reduced by up to $11.64 \%$ and $11.77 \%$, respectively, compared to that of the control specimen. Moreover, the addition of GO further reduced the porosity of ITZ and bulk paste

(3) The incorporation of GO could reduce the volume fraction of ITZ of mortar and reduce the porosity difference between ITZ and bulk paste. However, the volume fraction of pores in ITZ to total pores in mortar did not change significantly. This indicated that the GO could improve the performance of ITZ to some extent; however, the contribution of ITZ still could not be neglected when GO was involved

(4) The level of increase in compressive strength and the reduction in porosity were strongly correlated. The 
addition of GO reduced the influence of ITZ on the compressive strength. By considering the microfeatures of ITZ, the accuracy of prediction at macro level would be significantly improved for cementitious materials

\section{Data Availability}

The data used to support the findings of this study are included within the article.

\section{Conflicts of Interest}

The authors declare no conflict of interest.

\section{Acknowledgments}

This research work was financially supported by the National Natural Science Foundation of China (Grant Nos. 51878412, 51520105012, 51878413, 51678368, and 51508338), the Project of Department of Education of Guangdong Province (Grant Nos. 2014KZDXM051 and 2017GKTSCX064), and the Shenzhen R\&D Fund (Grant No. JCYJ20170818100641730). We also thank the Guangdong Provincial Key Laboratory of Durability for Marine Civil Engineering, College of Civil and Transportation Engineering, Shenzhen University, for providing facilities and equipment.

\section{References}

[1] H. Yang, M. Monasterio, H. Cui, and N. Han, "Experimental study of the effects of graphene oxide on microstructure and properties of cement paste composite," Composites Part A: Applied Science and Manufacturing, vol. 102, pp. 263-272, 2017.

[2] H. Peng, Y. Ge, C. S. Cai, Y. Zhang, and Z. Liu, "Mechanical properties and microstructure of graphene oxide cementbased composites," Construction and Building Materials, vol. 194, pp. 102-109, 2019.

[3] S. Lv, Y. Ma, C. Qiu, and Q. Zhou, "Regulation of GO on cement hydration crystals and its toughening effect," Magazine of Concrete Research, vol. 65, no. 20, pp. 1246-1254, 2013.

[4] Z. Pan, L. He, L. Qiu et al., "Mechanical properties and microstructure of a graphene oxide-cement composite," Cement and Concrete Composites, vol. 58, pp. 140-147, 2015.

[5] S. Lv, Y. Ma, C. Qiu, T. Sun, J. Liu, and Q. Zhou, "Effect of graphene oxide nanosheets of microstructure and mechanical properties of cement composites," Construction and Building Materials, vol. 49, no. 12, pp. 121-127, 2013.

[6] A. Elsharief, M. D. Cohen, and J. Olek, "Influence of aggregate size, water cement ratio and age on the microstructure of the interfacial transition zone," Cement and Concrete Research, vol. 33, no. 11, pp. 1837-1849, 2003.

[7] K. L. Scrivener, A. K. Crumbie, and P. Laugesen, "The interfacial transition zone (ITZ) between cement paste and aggregate in concrete," Interface Science, vol. 12, no. 4, pp. 411-421, 2004.

[8] K. Y. Liao, P. K. Chang, Y. N. Peng, and C. C. Yang, "A study on characteristics of interfacial transition zone in concrete,"
Cement and Concrete Research, vol. 34, no. 6, pp. 977-989, 2004.

[9] D. P. Bentz and E. J. Garboczi, "Simulation studies of the effects of mineral admixtures on the cement paste-aggregate Interfacial zone (SP-105)," ACI Materials Journal, vol. 88, no. 5, pp. 518-529, 1991.

[10] J. M. Gao, C. X. Qian, H. F. Liu, B. Wang, and L. Li, "ITZ microstructure of concrete containing GGBS," Cement and Concrete Research, vol. 35, no. 7, pp. 1299-1304, 2005.

[11] M. Kuroda, T. Watanabe, and N. Terashi, "Increase of bond strength at interfacial transition zone by the use of fly ash," Cement and Concrete Research, vol. 30, no. 2, pp. 253-258, 2000.

[12] M. Hu, J. Guo, J. Fan, P. li, and D. Chen, "Dispersion of triethanolamine-functionalized graphene oxide (TEA-GO) in pore solution and its influence on hydration, mechanical behavior of cement composite," Construction and Building Materials, vol. 216, pp. 128-136, 2019.

[13] X. Li, C. Li, Y. Liu et al., "Improvement of mechanical properties by incorporating graphene oxide into cement mortar," Mechanics of Advanced Materials and Structures, vol. 25, no. 15-16, pp. 1313-1322, 2018.

[14] BS EN 196-1, Methods of Testing Cement-Part 1: Determination of Strength, European Committee for Standardization, 2005.

[15] A. Leemann, B. Münch, P. Gasser, and L. Holzer, "Influence of compaction on the interfacial transition zone and the permeability of concrete," Cement and Concrete Research, vol. 36, no. 8, pp. 1425-1433, 2006.

[16] S. Yao, S. Hongfang, X. Weiting et al., "Influence of curing on the early-stage water evaporation and porosity gradient of pavement construction joint," Tumu Gongcheng Xuebao/China Civil Engineering Journal, vol. 48, pp. 119-124, 2015.

[17] H. S. Wong, M. K. Head, and N. R. Buenfeld, "Pore segmentation of cement-based materials from backscattered electron images," Cement and Concrete Research, vol. 36, no. 6, pp. 1083-1090, 2006.

[18] H. S. Wong, K. Matter, and N. R. Buenfeld, "Estimating the original cement content and water-cement ratio of Portland cement concrete and mortar using backscattered electron microscopy," Magazine of Concrete Research, vol. 65, no. 11, pp. 693-706, 2013.

[19] G. Prokopski and J. Halbiniak, "Interfacial transition zone in cementitious materials," Cement and Concrete Research, vol. 30, no. 4, pp. 579-583, 2000.

[20] E. J. Garboczi and D. P. Bentz, "Multiscale analytical/numerical theory of the diffusivity of concrete," Advanced Cement Based Materials, vol. 8, no. 2, pp. 77-88, 1998.

[21] D. P. Bentz and E. J. Garboczi, "Computer modelling of interfacial transition zone: microstructure and properties," in Engineering and Transport Properties of the Interfacial Transition Zone in Cementitious Composites. RILEM Report No. 20. Proceedings. Part 5. Chapter 20, pp. 349-385, Cedex, France, 1999.

[22] H. Ma, Multi-Scale Modeling of the Microstructure and Transport Properties of Contemporary Concrete, [Ph.D. thesis], Hong Kong University, 2013.

[23] B. Lu and S. Torquato, "Nearest-surface distribution functions for polydispersed particle systems," Physical Review A, vol. 45, no. 8 , pp. 5530-5544, 1992. 
[24] S. Diamond and J. Huang, "The ITZ in concrete - a different view based on image analysis and SEM observations," Cement and Concrete Composites, vol. 23, no. 2-3, pp. 179-188, 2001.

[25] P. Hui, G. E. Yaping, Y. Zhentian, L. Yang, and L. V. Yigang, "Mechanical properties and microstructure of graphene oxide reinforced cement-based composites," Acta Materiae Compositae Sinica, vol. 35, no. 8, pp. 2132-2139, 2018.

[26] J. D. Birchall, A. J. Howard, and K. Kendall, "Flexural strength and porosity of cements," Nature, vol. 289, no. 5796, pp. 388390, 1981.

[27] Y. C. Choi, J. Kim, and S. Choi, "Mercury intrusion porosimetry characterization of micropore structures of high-strength cement pastes incorporating high volume ground granulated blast-furnace slag," Construction and Building Materials, vol. 137, pp. 96-103, 2017.

[28] Z. Tian and J. Bu, "Mathematical model relating uniaxial compressive behavior of manufactured sand mortar to MIPderived pore structure parameters," The Scientific World Journal, vol. 2014, Article ID 736230, 9 pages, 2014.

[29] X. Chen, S. Wu, and J. Zhou, "Influence of porosity on compressive and tensile strength of cement mortar," Construction and Building Materials, vol. 40, no. 3, pp. 869-874, 2013.

[30] C. Lian, Y. Zhuge, and S. Beecham, "The relationship between porosity and strength for porous concrete," Construction and Building Materials, vol. 25, no. 11, pp. 4294-4298, 2011.

[31] R. Kumar and B. Bhattacharjee, "Porosity, pore size distribution and in situ strength of concrete," Cement and Concrete Research, vol. 33, no. 1, pp. 155-164, 2003. 